\title{
BMJ Open Cost-related non-adherence to prescribed medicines among older adults: a cross-sectional analysis of a survey in 11 developed countries
}

\author{
Steven G Morgan, Augustine Lee
}

To cite: Morgan SG, Lee A. Cost-related non-adherence to prescribed medicines among older adults: a crosssectional analysis of a survey in 11 developed countries. BMJ Open 2017;7:e014287. doi:10.1136/bmjopen-2016014287

- Prepublication history for this paper is available online. To view these files please visit the journal online (http://dx.doi.org/10.1136/ bmjopen-2016-014287).

Received 13 September 2016 Revised 22 December 2016 Accepted 5 January 2017

CrossMark

School of Population and Public Health, University of British Columbia, Vancouver, British Columbia, Canada

Correspondence to Dr Steven Morgan; steve.morgan@ubc.ca

\section{ABSTRACT}

Objectives: To assess the effects of costs on access to medicines in 11 developed countries offering different levels of prescription drug coverage for their populations.

Design: Cross-sectional study of data from the Commonwealth Fund 2014 International Health Policy Survey of Older Adults.

Setting: Telephone survey conducted in 11 highincome countries: Australia, Canada, France, Germany, the Netherlands, New Zealand, Norway, Sweden, Switzerland, the UK and the USA.

Participants: 22532 adults aged 55 and older and living in the community in studied countries.

Primary outcome measure: Self-reported costrelated non-adherence (CRNA) in the form of either not filling a prescription or skipping doses within the last 12 months because of out-of-pocket costs.

Results: Estimated prevalence of CRNA among all older adults varied from $<3 \%$ in the France, Norway, Sweden, Switzerland and the UK to $16.8 \%$ in the USA. Canada had the second highest national prevalence of CRNA (8.3\%), followed by Australia (6.8\%). Older adults in the USA were approximately six times more likely to report CRNA than older adults in the UK (adjusted OR=6.09; 95\% Cl 3.60 to 10.20). Older adults in Australia and Canada were also statistically significantly more likely to report CRNA than older adults in the UK. Across most countries, the prevalence of CRNA was higher among lower income residents and lower among residents over age 65 .

Conclusions: Observed differences in national prevalence of CRNA appear to follow lines of availability of prescription drug coverage and the extent of direct patient charges for prescriptions under available drug plans.

\section{INTRODUCTION}

Universal access to necessary medicines is an important goal of national health systems. ${ }^{1}$ Almost all developed countries provide universal coverage of prescription drugs; however, there are potentially important

\section{Strengths and limitations of this study}

- Study is based on a large, cross-national survey of self-reported cost-related non-adherence (CRNA) in 11 comparable, high-income countries.

- Crude and adjusted odds of CRNA are reported for all older adults and stratified by age and income groups.

- Differences in access to medicines are compared with the extent of coverage offered in countries studied.

- Survey data may be limited by response rates, recall bias and potential social desirability bias.

differences in the extent of coverage offered. ${ }^{2}$ Some countries apply various forms of cost-sharing on prescription drug purchases in the community setting, whereas others cover such prescriptions at little or no direct cost to patients. Furthermore, neither the USA nor Canada has thus far achieved universal coverage of essential medicines, leaving significant segments of the populations in those countries with effectively no prescription drug coverage at all. ${ }^{34}$

There are many reasons for patients to choose not to use a medication. ${ }^{5} 6$ Some of these reasons, including side effect, intolerance or preference for non-pharmacological treatment options, are ones that providers and policymakers should respect-particularly if based on reasoned decision-making by informed patients. Other reasons for not using medicines as prescribed are more problematic for healthcare providers and society as a whole. Costs are a common and problematic cause of prescription nonadherence, with studies showing that financial barriers to accessing necessary medications are correlated with worse health outcomes and increased use and cost of other health services. ${ }^{78}$ 
The purpose of this study was to assess the effects of direct patient costs on access to medicines in 11 developed countries in Europe, North America and Australasia. We hypothesise that cost-related access barriers will be higher in countries without universal coverage for pharmaceuticals (the USA and Canada) than in countries providing universal coverage of prescription drugs at little or no direct cost to patients (eg, the UK). Further, because many of the health systems studied (including the USA and Canada) provide greater coverage of medication costs for persons over age 65, we hypothesise that access will be higher and cross-national differences lower among that age group.

\section{METHODS}

This is a secondary, cross-sectional study of data from the Commonwealth Fund 2014 International Health Policy Survey of Older Adults. ${ }^{9}$ This survey included 11 high-income countries: Australia, Canada, France, Germany, the Netherlands, New Zealand, Norway, Sweden, Switzerland, the UK and the USA. It focused on older adults, defined as persons aged 55 and above.
Participants from all but two of the countries surveyed were eligible for universal health coverage that included universal coverage of outpatient prescription drugs-see table 1. Residents of the USA may or may not have either health or pharmaceutical coverage depending on their age, occupation, income and decision to enrol for coverage under the Affordable Care Act. ${ }^{3}$ Residents of Canada are eligible for universal public health insurance for medical and hospital care but may not have access to either public or private prescription drug coverage as such coverage varies in Canada by age, occupation, income and province of residence. ${ }^{10}$

Patient contributions for reimbursed prescriptions vary across the 11 countries included in this study-see table 1. General beneficiaries under Australia's universal public drug plan, for example, face a relatively high copayment of £21.91 (AU\$38.30) per prescription (or the full prescription cost if less than the copayment). In contrast, reimbursed prescriptions are available at little or no cost in several countries, including the Netherlands, New Zealand and parts of the UK.

Patient age can have direct or indirect impacts on available coverage for medicines in the countries

Table 1 Summary of outpatient prescription drug coverage in study countries, 2016

\begin{tabular}{|c|c|c|c|c|}
\hline Country & $\begin{array}{l}\text { Outpatient } \\
\text { prescription drug } \\
\text { coverage }\end{array}$ & $\begin{array}{l}\text { Dominant source of } \\
\text { pharmaceutical } \\
\text { financing }(\%)\end{array}$ & $\begin{array}{l}\text { Standard patient charges } \\
\text { for reimbursable } \\
\text { prescriptions }\end{array}$ & $\begin{array}{l}\text { Change in subsidy at age } \\
65+\end{array}$ \\
\hline Australia & Universal & Public (49\%) & $£ 21.91$ (AU\$38.30) & $\begin{array}{l}\text { Yes-lower copayment of } \\
£ 3.55 \text { (AU\$6.20) }\end{array}$ \\
\hline Canada & Non-universal & Mixed financing* & Varies by drug plan & $\begin{array}{l}\text { Eligible for public drug } \\
\text { coverage in several } \\
\text { provinces }\end{array}$ \\
\hline France & Universal & Social insurance $(70 \%)$ & $35-70 \%$ coinsurance & $\begin{array}{l}\text { Indirect-coinsurance } \\
\text { waved for chronic illness }\end{array}$ \\
\hline Germany & Universal & Social insurance (79\%) & $\begin{array}{l}£ 4.19-8.38(€ 5-10) \\
\text { copayment }\end{array}$ & $\begin{array}{l}\text { Yes-copayment } \\
\text { exemptions }\end{array}$ \\
\hline Netherlands & Universal & Social insurance (80\%) & None & No \\
\hline $\begin{array}{l}\text { New } \\
\text { Zealand }\end{array}$ & Universal & Public $(63 \%)$ & $£ 2.76(\mathrm{NZ} \$ 5)$ & $\begin{array}{l}\text { Indirect-no copayments } \\
\text { once household exceeds } \\
20 \text { prescriptions in year }\end{array}$ \\
\hline Norway & Universal & Public (57\%) & $38 \%$ coinsurance & $\begin{array}{l}\text { Indirect-annual patient } \\
\text { contribution capped at } £ 216 \\
\text { (kr2185) }\end{array}$ \\
\hline Sweden & Universal & Public (52\%) & $\begin{array}{l}£ 96.67(\mathrm{kr} 1100) \text { annual } \\
\text { deductible and } 10-50 \% \\
\text { coinsurance }\end{array}$ & $\begin{array}{l}\text { Indirect-annual patient } \\
\text { contribution capped at } \\
£ 193.34 \text { (kr2200) }\end{array}$ \\
\hline Switzerland & Universal & Social insurance (65\%) & $\begin{array}{l}\text { Annual deductible (chosen by } \\
\text { patient with insurance plan) } \\
\text { and } 10 \% \text { coinsurance }\end{array}$ & No \\
\hline UK & Universal & Public (66\%) & $\begin{array}{l}\text { None in Scotland, Wales and } \\
\text { Northern Ireland; } £ 8.20 \\
\text { copayment in England }\end{array}$ & $\begin{array}{l}\text { Yes-copayment } \\
\text { exemption in England }\end{array}$ \\
\hline USA & Non-universal & Private $(36 \%)$ & Varies by drug plan & $\begin{array}{l}\text { Yes-eligible for Medicare } \\
\text { drug benefit }\end{array}$ \\
\hline
\end{tabular}


studied. Being over age 65 can have the direct effect of increasing eligibility for public drug subsidies in the USA and Canada. Older age can also have a direct effect on patient charges under otherwise universal systems of drug coverage: such as in Australia, Germany and England, where prescription charges are reduced or eliminated for older patients. Finally, older patients may benefit from policies aimed at limiting the out-of-pocket cost of medicines for patients with significant pharmaceutical needs, such as in France, New Zealand, Norway and Sweden.

\section{Data sources}

We used the Commonwealth Fund 2014 International Health Policy Survey of Older Adults. ${ }^{9}$ This survey was conducted between March and May 2014 by telephone to landline and mobile numbers. The survey was based on a common questionnaire that was translated and adjusted for country-specific wording as required. The survey transcript is available from the Commonwealth Fund. ${ }^{11}$ Participants in the survey had to be aged 55 or older and living in the community.

\section{Variables}

Our primary outcome variable was whether or not a survey respondent had experienced cost-related nonadherence (CRNA). Survey respondents who reported that they had received at least one prescription and that they had either not filled a prescription or had skipped doses within the last 12 months because of out-of-pocket costs were considered to have experienced CRNA. Those who responded that they 'did not know' to whether or not they did not fill a prescription or skipped doses because of costs were coded as not having experienced CRNA. To the best of our knowledge, survey questions of this sort are the only comparable access measures for cross-national studies of CRNA.

Informed by existing literature and models of access to care and health services usage, ${ }^{5} 612$ we selected survey questions concerning age, sex, income and health status as potential predictors of CRNA. We classified age into two groups of primary interest: aged 55-64 versus age $65+$. We included self-reported income using the Commonwealth Fund's definitions: above average, average and below average. We aggregated self-reported health status into three categories: very good, good and either fair or poor.

In all models comparing CRNA across countries, we used residents of the UK as the reference group.

\section{Statistical methods}

We computed the sample-weighted CRNA prevalence for each country. Weighting was done with the Commonwealth Fund sample weights to reflect general populations at the national level in each country.

We also ran sample-weighted logistic regressions to determine the associations between CRNA and potential predictors (age, sex, income and health status). We performed pooled and stratified analyses based on age and based on income. For all analyses, a value of $\mathrm{p}<0.05$ was considered statistically significant. We report Nagelkerke/Cragg pseudo $\mathrm{R}^{2}$ statistics for each regression. All analyses were performed using SPSS (Statistics V.20) (IBM Analytics, New York, USA).

In an effort to increase the power of analyses of crossnational differences, we performed all analyses using clusters of countries with similar levels of drug coverage as comparison groups. Those analyses did not alter the nature of the findings reported below.

\section{RESULTS}

Table 2 lists summary characteristics of the 22532 survey respondents with complete survey data, stratified by country of residence. Slightly more than half $(57 \%)$ of all survey respondents were over age 65: range 52.3\% (Canada) to $61.5 \%$ (Sweden). Approximately half $(52 \%)$ were female respondents: range $47.5 \%$ (the Netherlands) to $56.1 \%$ (the UK). Just under half of the survey respondents $(47.9 \%)$ reported having below-average income: range $38.9 \%$ (the Netherlands)

Table 2 Characteristics of respondents providing complete data in the 2014 Commonwealth Fund International Health Policy Survey of Older Adults, by country of respondent

\begin{tabular}{lrlllll}
\hline Country & N & \% Aged 65+ & \% Female & \% Below average income & \% Fair or poor health & \% 1+ prescription \\
\hline Australia & 2598 & 56.9 & 52.8 & 59.1 & 50.8 & 79.3 \\
Canada & 4696 & 52.3 & 53.0 & 51.1 & 51.5 & 78.7 \\
France & 1328 & 57.5 & 55.1 & 41.2 & 18.9 & 75.8 \\
Germany & 815 & 60.9 & 53.6 & 48.6 & 22.7 & 78.0 \\
Netherlands & 862 & 54.7 & 47.5 & 38.9 & 21.1 & 76.0 \\
New Zealand & 675 & 55.2 & 53.2 & 46.9 & 56.3 & 69.4 \\
Norway & 927 & 57.2 & 51.3 & 54.1 & 34.7 & 76.8 \\
Sweden & 6597 & 61.5 & 52.1 & 40.9 & 35.7 & 75.5 \\
Switzerland & 1682 & 58.1 & 54.2 & 60.5 & 36.1 & 73.0 \\
UK & 759 & 59.2 & 56.1 & 44.0 & 44.1 & 73.4 \\
USA & 1593 & 52.7 & 53.8 & 45.0 & 40.5 & 84.6 \\
All countries & 22532 & 57.2 & 52.8 & 47.9 & & 76.6
\end{tabular}


to $60.5 \%$ (Switzerland). The share of survey respondents reporting being of fair or poor health ranged from a low of $18.9 \%$ in France to a high of $56.3 \%$ in New Zealand. Finally, approximately three in four survey respondents $(76.6 \%)$ reported receiving one or more prescription in the past 12 months: range $69.4 \%$ (New Zealand) to $84.6 \%$ (the USA).

As shown in table 3 , the estimated prevalence of CRNA among all older adults varied from $<3 \%$ in France, Norway, Sweden, Switzerland and the UK to $16.8 \%$ in the USA. Canada had the second highest national prevalence of CRNA $(8.3 \%)$, followed by Australia (6.8\%). Before adjusting for potential predictors of CRNA, the levels of CRNA in the USA, Canada and Australia were significantly higher than the reference country, the UK. Relative to the UK, there were no other statistically significant differences in crude estimates of the prevalence of CRNA.
In the logistic regression model with respondents of all ages and income levels from all countries, the adjusted odds of reporting CRNA were statistically significantly higher among people who were younger (age 5465 ), of average or below-average income and of poor health (results not shown in table). Sex was not a significant predictor of CRNA in the model.

Controlling for age, sex, health status and household income, adults aged 55 and older in the USA were approximately six times more likely to report CRNA than adults aged 55 and older in the UK (adjusted OR $(\mathrm{AOR})=6.09 ; 95 \%$ CI 3.60 to 10.20$)$. Adults aged 55 and older in the Australia and Canada were also statistically significantly more likely to report CRNA than similarly aged adults in the UK. Finally, the adjusted odds of CRNA among adults aged 55 and older in France were significantly lower than in the UK $(\mathrm{AOR}=0.47 ; 95 \%$ CI 0.23 to 0.94$)$.

Table 3 National prevalence and adjusted odds of cost-related non-adherence among respondents to the 2014 Commonwealth Fund International Health Policy Survey of Older Adults

\begin{tabular}{|c|c|c|c|}
\hline Country & CRNA \% & Unadjusted OR $(95 \% \mathrm{Cl})$ & Adjusted OR (95\% Cl) \\
\hline Australia & 6.8 & 2.37 (1.14 to 3.98$)$ & 2.17 (1.29 to 3.68$)$ \\
\hline Canada & 8.3 & $2.92(1.77$ to 4.84$)$ & 2.76 (1.66 to 4.59$)$ \\
\hline France & 1.6 & $0.54(0.27$ to 1.08$)$ & $0.47(0.24$ to 0.95$)$ \\
\hline Germany & 3.7 & 1.22 (0.64 to 2.33$)$ & $1.00(0.52$ to 1.91$)$ \\
\hline Netherlands & 4.0 & $1.35(0.72$ to 2.53$)$ & $1.19(0.63$ to 2.24$)$ \\
\hline New Zealand & 4.8 & $1.62(0.85$ to 3.10$)$ & $1.69(0.88$ to 3.24$)$ \\
\hline Norway & 2.4 & 0.80 (0.41 to 1.59$)$ & $0.66(0.33$ to 1.31$)$ \\
\hline Sweden & 2.4 & 0.78 (0.47 to 1.32$)$ & $0.80(0.47$ to 1.36$)$ \\
\hline Switzerland & 2.9 & 0.97 (0.54 to 1.75$)$ & 0.86 (0.48 to 1.57$)$ \\
\hline UK & 3.1 & Reference & Reference \\
\hline USA & 16.8 & 6.47 (3.89 to 10.78$)$ & $6.10(3.64$ to 10.20$)$ \\
\hline
\end{tabular}

Results reported in bold are significant at $p=0.05$.

Adjusted ORs based on sample-weighted logistic regression models that control for age group, sex, health status and household income. CRNA, cost-related non-adherence, sample-weighted prevalence.

Table 4 National prevalence and adjusted odds of cost-related non-adherence among respondents to the 2014 Commonwealth Fund International Health Policy Survey of Older Adults, stratified by income

\begin{tabular}{|c|c|c|c|c|c|c|}
\hline \multirow[b]{2}{*}{ Country } & \multicolumn{2}{|c|}{ All incomes } & \multicolumn{2}{|c|}{ Below-average income } & \multicolumn{2}{|c|}{ Average income or above } \\
\hline & CRNA \% & Adjusted OR (95\% Cl) & CRNA \% & Adjusted OR (95\% Cl) & CRNA \% & Adjusted OR (95\% CI) \\
\hline Australia & 6.8 & 2.17 (1.28 to 3.67$)$ & 7.6 & 3.61 (1.57 to 8.26$)$ & 5.5 & $1.48(0.74$ to 2.98$)$ \\
\hline Canada & 8.3 & 2.76 (1.66 to 4.59$)$ & 11.7 & $5.43(2.40$ to 12.35$)$ & 4.5 & $1.23(0.64$ to 2.40$)$ \\
\hline France & 1.6 & $0.47(0.23$ to 0.94$)$ & 0.7 & $0.22(0.05$ to 0.95$)$ & 2.5 & $0.57(0.25$ to 1.30$)$ \\
\hline Germany & 3.7 & $0.99(0.52$ to 1.91$)$ & 5.3 & $1.80(0.70$ to 4.65$)$ & 2.0 & $0.52(0.19$ to 1.44$)$ \\
\hline Netherlands & 4.0 & $1.18(0.62$ to 2.23$)$ & 5.8 & $1.99(0.76$ to 5.21$)$ & 2.9 & $0.73(0.31$ to 1.75$)$ \\
\hline New Zealand & 4.8 & $1.68(0.87$ to 3.23$)$ & 5.3 & $2.43(0.91$ to 6.49$)$ & 4.3 & $1.32(0.54$ to 3.23$)$ \\
\hline Norway & 2.4 & $0.66(0.33$ to 1.31$)$ & 2.7 & 0.99 (0.36 to 2.72$)$ & 2.2 & $0.52(0.19$ to 1.39$)$ \\
\hline Sweden & 2.4 & 0.80 (0.47 to 1.37$)$ & 3.6 & $1.53(0.66$ to 3.53$)$ & 1.5 & $0.41(0.20$ to 0.81$)$ \\
\hline Switzerland & 2.9 & 0.86 (0.48 to 1.56$)$ & 3.4 & $1.46(0.60$ to 3.56$)$ & 2.2 & $0.59(0.24$ to 1.44$)$ \\
\hline UK & 3.1 & Reference & 2.3 & Reference & 3.4 & Reference \\
\hline USA & 16.8 & 6.09 (3.60 to 10.20$)$ & 24.9 & $10.87(4.76$ to 25.00$)$ & 9.7 & 3.30 (1.68 to 6.49$)$ \\
\hline Pseudo $\mathrm{R}^{2}$ & & 0.148 & & 0.165 & & 0.086 \\
\hline
\end{tabular}

Results reported in bold are significant at $p=0.05$.

Adjusted ORs are from sample-weighted logistic regression models. Pooled income model controls for age group, sex, health status and household income (not shown). Income-stratified models control for age, sex and health status.

CRNA, cost-related non-adherence, sample-weighted prevalence. 
Table 4 lists national prevalence and adjusted odds of CRNA stratified by income. Lower incomes were associated with higher levels of CRNA in most countries, particularly in the USA and Canada, where the prevalence of CRNA among older adults with below-average incomes were $24.9 \%$ and $11.7 \%$, respectively. In both income-stratified logistic regressions, the adjusted odds of reporting CRNA were statistically significantly higher among people who were aged 55-64, and among people of poor health (results not shown in table). Sex was not a significant predictor in either income-stratified model. After adjusting for age, sex and health status, low-income residents of the USA, Canada and Australia were significantly more likely to experience CRNA than low-income residents of the UK. Among higher income residents, the adjusted odds of CRNA were higher only in the USA relative to the UK (AOR=3.30; 95\% CI 1.68 to 6.47). Adjusted odds of CRNA among higher income adults in Sweden were significantly lower than among higher income adults in the UK.

Table 5 lists national prevalence and adjusted odds of CRNA stratified by age. Many surveyed countries had almost double the levels of CRNA among adults aged 55-64 than among adults aged 65 and older. In both age-specific logistic regressions, the adjusted odds of reporting CRNA were statistically significantly higher among people who were of average or below average income and of poor health (results not shown in table). Being male was associated with lower odds of CRNA in the regression for respondents aged 55-64 (AOR=0.74; $95 \%$ CI 0.61 to 0.89 ) but not in the regression for respondents aged 65 and older. Despite the withincountry differences by age, the direction of statistically significant cross-national differences in the adjusted odds of CRNA were generally the same for the two age-stratified logistic regression models that controlled for sex, health status and household income. One exception was that adjusted odds of CRNA among French residents aged 55-64 was not significantly different from like residents of the UK.

\section{DISCUSSION}

Using the Commonwealth Fund 2014 International Health Policy Survey of Older Adults, we found significant levels of variations in cost-related barriers to filling prescriptions within and across 11 comparable countries. The national prevalence of CRNA among all adults aged 55 and older varied from $<3 \%$ in the France, Norway, Sweden, Switzerland and the UK to $16.8 \%$ in the USA. Higher levels of CRNA may be associated with worse health outcomes and increased demands on other components of the healthcare system as other studies have shown that financial barriers can impede the use of essential, preventative medications as well as drugs taken for symptom relief. ${ }^{13} 14$

Adjusted odds of CRNA did not differ significantly among most of the countries in this study. However, with and without adjustments for possible predictors of CRNA, the odds of CRNA in the USA, Canada and Australia were significantly higher than in the UK, our reference country. Across most countries, the prevalence of CRNA was higher among lower income residents and lower among residents over age 65 .

Our results are consistent with studies based on older surveys in individual countries and comparisons of the USA and Canada. With 2002 and 2007 survey data, Kennedy and Morgan found that CRNA is more common in the USA than in Canada, attributing the difference to differences in the availability of health and drug coverage. ${ }^{15}{ }^{16}$ In a number of previous studies using county-specific data sources, lower income has been associated with greater likelihood of CRNA. ${ }^{5} 6$ Similarly, many, though not all, studies using countyspecific data have found that patients over age 60 or 65

Table 5 National prevalence and adjusted odds of cost-related non-adherence among respondents to the 2014 Commonwealth Fund International Health Policy Survey of Older Adults, stratified by age

\begin{tabular}{|c|c|c|c|c|c|c|}
\hline \multirow[b]{2}{*}{ Country } & \multicolumn{2}{|c|}{ All ages $(55+)$} & \multicolumn{2}{|c|}{ Ages 55 to 64} & \multicolumn{2}{|l|}{ Ages 65+ } \\
\hline & $\overline{\text { CRNA } \%}$ & Adjusted OR (95\% Cl) & CRNA \% & Adjusted OR (95\% Cl) & $\overline{\text { CRNA } \%}$ & Adjusted OR (95\% Cl) \\
\hline Australia & 6.8 & 2.17 (1.28 to 3.67$)$ & 8.2 & 2.07 (1.00 to 4.31$)$ & 4.4 & 2.31 (1.09 to 4.88$)$ \\
\hline Canada & 8.3 & 2.76 (1.66 to 4.59$)$ & 11.6 & 3.18 (1.57 to 6.46$)$ & 5.3 & 2.25 (1.08 to 4.69$)$ \\
\hline France & 1.6 & 0.47 (0.23 to 0.94$)$ & 3.4 & 0.69 (0.28 to 1.72$)$ & 1.5 & $0.23(0.07$ to 0.76$)$ \\
\hline Germany & 3.7 & $0.99(0.52$ to 1.91$)$ & 3.8 & $0.61(0.23$ to 1.67$)$ & 4.2 & $1.46(0.61$ to 3.49$)$ \\
\hline Netherlands & 4.0 & $1.18(0.62$ to 2.23$)$ & 4.0 & $1.20(0.51$ to 2.88$)$ & 2.9 & 1.17 (0.46 to 2.99$)$ \\
\hline New Zealand & 4.8 & 1.68 (0.87 to 3.23$)$ & 7.5 & 1.83 (0.76 to 4.44$)$ & 3.4 & $1.48(0.56$ to 3.49$)$ \\
\hline Norway & 2.4 & 0.66 (0.33 to 1.31$)$ & 3.8 & $0.63(0.24$ to 1.68$)$ & 1.9 & $0.68(0.26$ to 1.82$)$ \\
\hline Sweden & 2.4 & 0.80 (0.47 to 1.37$)$ & 3.9 & 0.94 (0.45 to 1.97$)$ & 1.8 & 0.68 (0.33 to 1.44$)$ \\
\hline Switzerland & 2.9 & 0.86 (0.48 to 1.56$)$ & 2.9 & $0.74(0.32$ to 1.75$)$ & 2.5 & $0.98(0.43$ to 2.26$)$ \\
\hline UK & 3.1 & Reference & 4.4 & Reference & 2.3 & Reference \\
\hline USA & 16.8 & $6.09(3.60$ to 10.20$)$ & 22.2 & $5.45(2.65$ to 11.21$)$ & 12.0 & 7.19 (3.43 to 15.07$)$ \\
\hline Pseudo $\mathrm{R}^{2}$ & & 0.148 & & 0.149 & & 0.112 \\
\hline
\end{tabular}

Results reported in bold are significant at $\mathrm{p}=0.05$.

Adjusted ORs are from sample-weighted logistic regression models. Pooled age model controls for age group, sex, health status and household income (not shown). Age-stratified models control for sex, health status and household income.

CRNA, cost-related non-adherence, sample-weighted prevalence. 
are more likely to comply with medications when compared with younger patients. ${ }^{5} 6$

Observed differences in national prevalence of CRNA appear to follow lines of availability of prescription drug coverage and the extent of direct patient charges for prescriptions under available drug plans. Previous studies have shown that introducing or increasing direct patient charges is associated with reduced use of prescribed medications. ${ }^{17}$ All of the countries surveyed that provide outpatient prescriptions at relatively low cost to patients had comparable levels of CRNA-none being significantly greater than the $~ 3 \%$ CRNA prevalence observed in the UK.

In contrast to other health systems, many residents of the USA and Canada do not have drug coverage. ${ }^{3} 4$ Americans and Canadians who do have private or public drug coverage face varying levels of deductibles, coinsurance or copayments. In some cases, this can include reference-based reimbursement charges that stem from the dispensation of brand-name drugs when generic alternatives are available; however, couponing by manufacturers is an attempt to reduce the burden of such charges for sponsoring brands. ${ }^{18} 19$ Consistent with the hypothesis that higher direct costs to patients are associated with increased likelihood of CRNA, the crude and adjusted odds of CRNA in the USA and Canada were significantly greater than the UK (and other comparator countries with universal coverage of medicines at little direct cost to patients).

The differences in CRNA between the UK and either the USA or Canada were lower for patients over age 65, which is consistent with the hypothesis that Americans' and Canadians' increased eligibility for drug coverage at that age may increase their access to medicines and thereby reduce cross-national disparities in levels of CRNA. Further, there was no significant difference in the adjusted odds of CRNA among higher income Canadians aged 55 and older versus similar residents of the UK. This too is consistent with the hypothesis that the availability and extent of drug coverage is a predictor of CRNA, regardless of income, because private insurance for prescription drugs is more prevalent among higher income Canadians than among lower income Canadians. ${ }^{10}$

We also found that the odds of CRNA were higher in Australia than in the UK. As patients face relatively high standard copayments under Australia's universal drug benefit plan, this finding is also consistent with the hypothesis that CRNA is inversely related to the extent of drug coverage available.

\section{LIMITATIONS}

Our study is not without limitations. CRNA is a complex phenomenon, driven by a combination of individual and system-level factors, not all of which can be captured in a brief telephone survey that covered a wide range of countries and topics concerning healthcare experiences. Statistical models based on such data will explain some but not all of the individual-level variation in CRNA experiences, which explains the modest $R^{2}$ statistics. Analyses such as these are best suited to defining patient categories and system-level factors associated with elevated risk of CRNA, rather than being viewed as an attempt to predict whether specific individuals within specific context will experience CRNA.

As a random-digit-dialled telephone survey, response rates varied from $16 \%$ (Norway) to $60 \%$ (Switzerland) across countries (IQR 25-28\%), potentially introducing participation biases in the samples. ${ }^{9}$ The direction of that bias is unknown; however, study characteristics and estimated rates of CRNA are comparable for countries with low response rates (Norway) and those with high response rates (Switzerland). Furthermore, estimated CRNA rates for the USA and Canada are comparable to previous studies drawing on surveys with greater response rates. 151620

Survey data is also limited by recall bias and potential social desirability bias. It is possible, for example, that North Americans feel less pressure to report that they filled prescriptions written for them than European colleges. For example, the relatively low rates of selfreported poor health and CRNA found in France may be partially attributed to cross-national differences in social desirability biases. We do not believe that such potential cultural differences in survey response bias would be sufficient to explain the significant differences in national prevalence of CRNA observed in this study.

Finally, the telephone survey data do not identify which types of medication were skipped as a result of costs. It is possible that some of the foregone medications could have been discretionary (eg, for mild symptom relief) or even potentially harmful (eg, potentially inappropriate prescriptions for older populations). Further international comparative work, involving more detailed survey questions concerning medication use for particular conditions, would help to determine the extent to which international differences in access to medicines reflect differences in the use of essential versus non-essential medications.

\section{CONCLUSION}

Our study finds that access to medicines varies within and across countries in ways consistent with the hypothesis that higher costs to patients, particularly low-income patients, are associated with higher risks of cost-related access barriers. Access to medications in the USA, Canada and, to a lesser extent, Australia is below international comparators. Access in the USA and Canada might be improved with universal coverage of medication costs. Access in Australia might be improved by reducing the standard copayment under the existing universal drug benefit programme there.

Twitter Follow Steve Morgan @SteveUBC

Contributors SGM is responsible for study concept and design, interpretation of results and preparation of manuscript. AL assisted with study design, 
analysis of data, interpretation of results and editing of manuscript for important intellectual content.

Funding This work was supported in part by a research grant from the Canadian Institutes of Health Research, Institute of Gender and Health (ClHR DC0150GP), and by the Commonwealth Fund (20160646), a national, private foundation based in New York City.

Disclaimer The views presented here are those of the author and not necessarily those of The Commonwealth Fund, its directors, officers, or staff. The funding agency had no role in study design, analysis, or preparation of the paper.

Competing interests None declared.

Provenance and peer review Not commissioned; externally peer reviewed.

Data sharing statement Survey data are available from the Commonwealth Fund. Regression results not reported in the paper are available from the authors.

Open Access This is an Open Access article distributed in accordance with the Creative Commons Attribution Non Commercial (CC BY-NC 4.0) license, which permits others to distribute, remix, adapt, build upon this work noncommercially, and license their derivative works on different terms, provided the original work is properly cited and the use is non-commercial. See: http:// creativecommons.org/licenses/by-nc/4.0/

\section{REFERENCES}

1. Bigdeli M, Peters DH, Wagner AK. (eds). Medicines in health systems: advancing access, affordability and appropriate use. Geneva: World Health Organization, 2014.

2. Barnieh L, Clement F, Harris A, et al. A systematic review of cost-sharing strategies used within publicly-funded drug plans in member countries of the organisation for economic co-operation and development. PLoS ONE 2014;9:e90434

3. United States Department of Health and Human Services. Health Insurance Marketplaces 2016 Open Enrollment Period: Final Enrollment Report. Issue Brief. Washington: Office of the Assistant Secretary for Planning and Evaluatio, 2016.

4. Morgan SG, Gagnon MA, Mintzes B, et al. A better prescription: advice for a national strategy on pharmaceutical policy in Canada. Healthc Policy 2016;12:18-36.
5. Jin J, Sklar GE, Min Sen Oh V, et al. Factors affecting therapeutic compliance: a review from the patient's perspective. Ther Clin Risk Manag 2008;4:269-86.

6. Briesacher BA, Gurwitz JH, Soumerai SB. Patients at-risk for cost-related medication nonadherence: a review of the literature. J Gen Intern Med 2007;22:864-71.

7. Goldman DP, Joyce GF, Zheng Y. Prescription drug cost sharing associations with medication and medical utilization and spending and health. JAMA 2007;298:61-9.

8. Kesselheim AS, Huybrechts KF, Choudhry NK, et al. Prescription drug insurance coverage and patient health outcomes: a systematic review. Am J Public Health 2015;105:e17-30.

9. Osborn R, Moulds D, Squires D, et al. International survey of older adults finds shortcomings in access, coordination, and patient-centered care. New York: The Commonwealth Fund, 2014.

10. Barnes S, Anderson L. Low earnings, unfilled prescriptions employer-provided health benefit coverage in Canada. Toronto: Wellesley Institute, 2015

11. SSRS. 2014 International Health Policy Survey of Older Adults New York: Commonwealth Fund, 2014 (updated 1 December 2014). http://www.commonwealthfund.org/ /media/files/surveys/2014/ 2014-ihp-questionnaire_final.pdf (accessed 25 Oct 2016)

12. Andersen RM. Revisiting the behavioral model and access to medical care: does it matter? J Health Soc Behav 1995;36:1-10.

13. Williams J, Steers WN, Ettner SL, et al. Cost-related nonadherence by medication type among Medicare Part $D$ beneficiaries with diabetes. Med Care 2013;51:193-8.

14. DiMatteo MR. Variations in patients' adherence to medical recommendations: a quantitative review of 50 years of research. Med Care 2004;42:200-9.

15. Kennedy J, Morgan S. A cross-national study of prescription nonadherence due to cost: data from the joint Canada-United States survey of health. Clin Ther 2006;28:1217-24.

16. Kennedy J, Morgan S. Health care access in three nations: Canada, insured America, and uninsured America. Int $J$ Health Serv 2006;36:697-717.

17. Austvoll-Dahlgren A, Aaserud M, Vist G, et al. Pharmaceutical policies: effects of cap and co-payment on rational drug use. Cochrane Database Syst Rev 2008;(1):CD007017.

18. Starner $\mathrm{Cl}$, Alexander GC, Bowen $\mathrm{K}$, et al. Specialty drug coupons lower out-of-pocket costs and may improve adherence at the risk of increasing premiums. Health Aff (Millwood) 2014;33:1761-9.

19. Ross JS, Kesselheim AS. Prescription-drug coupons-no such thing as a free lunch. N Engl J Med 2013;369:1188-9.

20. Law MR, Cheng L, Dhalla IA, et al. The effect of cost on adherence to prescription medications in Canada. CMAJ 2012;184 297-302. 